Supporting information for:

\title{
In Situ Surface Enhanced Infrared Absorption Spectroscopy for the Analysis of the Adsorption and Desorption Process of Au Nanoparticles on the $\mathrm{SiO}_{2} / \mathrm{Si}$ surface
}

\author{
Dominik Enders, Tadaaki Nagao, Tomonobu Nakayama, and Masakazu Aono
}

\section{S1 Detailed description of the sample preparation}

$100 \mathrm{ml}$ of $1 \mathrm{mM}$ solution of hydrogen tetrachloroaurate $\left(\mathrm{HAuCl}_{4}\right.$, Sigma Aldrich \#25,416-9) in $\mathrm{D}_{2} \mathrm{O}$ (99.9\%, Cambridge Isotope Laboratories Inc., \#DLM-4-1000) were heated under refluxing conditions until boiling, using an oil bath. Then $10 \mathrm{ml}$ of $38.8 \mathrm{mM}$ solution of tri-sodium citrate $\left(\mathrm{C}_{6} \mathrm{H}_{5} \mathrm{Na}_{3} \mathrm{O}_{7}\right.$, Merck \# 106448) in $\mathrm{D}_{2} \mathrm{O}$ at room temperature were added while stirring. The tri-sodium citrate is known to reduce the $\mathrm{HAuCl}_{4}$ to $\mathrm{Au}$ growing to nearly spherical AuNP having a size of $\mathrm{d}=11 \mathrm{~nm} \pm 1 \mathrm{~nm}$ (TEM).

Prior to the experiment the ATR crystal (Si hemisphere with naturally grown oxide layer) was ultrasonically cleaned in methanol and then put into $10 \%$ solution of (3aminopropyl)triethoxysilane (APTES, Merck \#821619) in methanol for one hour, followed by thoroughly rinsing with methanol and 10 minutes of ultrasonically cleaning of the ATR crystal in methanol to remove any excess amount of APTES. The ATR crystal was then rinsed again with methanol, let dry in air, and put into $\mathrm{D}_{2} \mathrm{O}$ for 10 minutes. 